\title{
SAN FRANCISCO DE ASÍS Y EL TRACOMA
}

\author{
SAMPEDRO A ${ }^{1}$, BARBÓN JJ ${ }^{1}$
}

Francisco Assisi (Asís 1182-1226) es el fundador de la orden franciscana, además, con la colaboración de santa Clara, fundó la rama femenina de su orden, que recibió el nombre de clarisas.

Hijo de un rico mercader llamado Pietro di Bernardone, Francisco era un joven mundano de cierto renombre en su ciudad. En 1202 fue encarcelado por unos meses a causa de su participación en un altercado entre las ciudades de Asís y Perugia. Tras este lance, aquejado por una enfermedad e insatisfecho con el tipo de vida que llevaba, decidió entregarse al apostolado y servir a los pobres.

Cuando, en 1219, el Santo se unió a la V Cruzada, en Egipto, contrajo una grave enfermedad de ojos una oftalmía egipciaca o mal egipcio «a consecuencia de lo que sufrió por la fatiga del viaje, en el

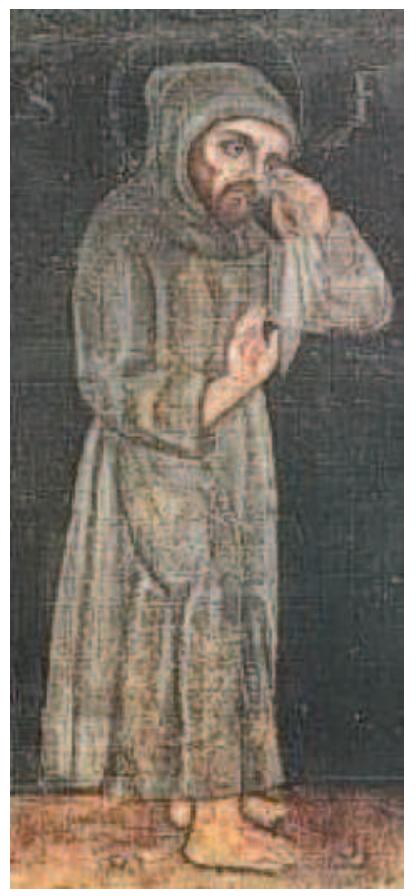

Retrato de San Francisco de Asís Santuario Franciscano del Belén - Greccio (Rieti). que, tanto de ida como de vuelta, tuvo que soportar grandes calores», (probablemente una conjuntivitis tracomatosa, y no un glaucoma secundario o una iritis producto de la tuberculosis) y, además, la malaria, en forma de cuartanas.

La descripción que del proceso hacia de oídas Enrique de Avranches, era de:

«un dolor insufrible oprime el nervio óptico,

los humores malignos y corrompidos enrojecen la pupila,

la inflamación de los párpados deforma la visión, la desazón hace vibrar la mirada.»

Desde finales de 1223, los padecimientos del Santo, tanto el ocular como la malaria, se fueron agravando y trajeron consigo enfermedades del hígado y del bazo. Recurrir a la asistencia de médicos le hubiera parecido como una forma de querer estorbar con cuidados y afanes terrenos la acción de Dios en su vida, pero los hermanos aconsejaban con insistencia al Santo que aceptase ser visitado por un médico y se dirigió a Rieti para curarse los ojos. Antes de dirigirse a Rieti, fué al monasterio de San Damián a confortar a santa Clara y estando allí «a la noche siguiente, enfermó tan gravemente de los ojos, que no podía soportar ninguna luz», le acondicionaron una celdilla de esteras que le aseguraba una oscuridad total. El paciente yació en la oscuridad de la celdilla durante más de cincuenta días, sin poder soportar la luz del sol ni el resplandor del fuego; sufría «grandes dolores en los ojos día y noche, de modo que casi no podía descansar ni dormir durante la noche».

Aunque su enfermedad se había agravado mucho, colocaron a Francisco sobre una cabalgadura y lo sostuvieron desde ambos lados durante el viaje «Francisco llevaba la cabeza cubierta con un capuchón que le habían confeccionado los hermanos; y como no podía soportar la claridad del día por los insufribles dolores provenientes de la enfermedad de los ojos, tapaba sus ojos con una venda de lana y lino cosida al capucho».

\footnotetext{
${ }^{1}$ Licenciado en Oftalmología. Servicio de Oftalmología Hospital San Agustín de Avilés. Asturias. España.

E-mail: jjbarbon@telecable.es
} 
Cuando el cirujano visitó al Santo encontró un ojo más enfermo que otro, por lo que propuso «cauterizar la parte superior de la mejilla hasta el entrecejo del ojo que estaba más afectado por el mal».

El cirujano «toma en las manos el hierro candente y tórrido, cuando crepitante, penetra en la tierna carne, y el cauterio se extiende, sin solución de continuidad, de la oreja a la sobreceja» asombrandose el cirujano de la increíble resistencia de aquel enfermo debilitado en extremo.

«En el caso del tracoma en su primer estadio el ojo produce gran cantidad de material infectante que elimina mediante las lágrimas y secreciones; éstas son, por tanto, la principal fuente de infección». En el segundo estadio, es decir, en el llamado tracoma declarado y generalizado, «se produce generalmente un exudado conjuntival de aspecto mucoso; en algunos períodos puede manifestarse una sintomatología catarral imponente, con abundante formación de exudado de carácter a veces purulento». Sin negar la presencia de fuertes dolores «que se propagan por el área de la primera rama del trigémino» en los casos en que el tracoma presenta la complicación de la membrana corneal, parece evidente que el principal propósito del cirujano fue bloquear el aflujo de la exudación purulenta en los ojos. Pero ni siquiera los médicos de entonces estaban de acuerdo. Alguno juzgó completamente inútil la intervención: «... y así fue, pues de nada le aprovechó»; «también otro médico le perforó las dos orejas, sin resultado alguno positivo».

En cuanto al tratamiento terapéutico al que sometieron al enfermo, el biógrafo transmite algunos datos dignos de atención: «... y en tal forma había penetrado el mal, que para cualquier remedio hacía falta muchísimo ingenio y procedimientos dolorosí- simos. De hecho sufrió cauterios en varias partes de la cabeza, le sajaron las venas, le pusieron emplastos, le inyectaron colirios; en lugar de proporcionarle alivio, estas intervenciones le perjudicaban casi siempre».

En la primavera de 1226 fray Elías pretendía que aquel paciente más muerto que vivo se sometiese a otro extenuante viaje hasta Siena «en busca de remedio para los ojos».

Según la tradición cristiana muchos ciegos recobran la vista de forma milagrosa por la mediacion del Santo de Asis: una mujer llamada Sibilia, un ciego de Spello, una mujer en Camerino privada por completo de la vista en el ojo derecho, otra mujer de Gubbio, un ciudadano de Asís y un tal Albertino de Narni había quedado totalmente ciego.

Los estudios realizados por el Oftalmólogo español Antonio Ros, experto en tracoma y que vivió exiliado en Mexico tras la Guerra Civil concluyen que San Francisco tuvo esta enfermedad, basándose en ello escribió una pequeña obra novelada sobre la vida del Santo en 1959, figurando la ceguera y el tracoma como hilo conductor de la misma.

\section{BIBLIOGRAFÍA}

1. Schmucki O. Enfermedades que sufrió San Francisco de Asís antes de su estigmatización. Selecciones de Franciscanismo. 1987; 16: 287-323.

2. Schmucki O. Las enfermedades de San Francisco durante los últimos años de su vida. Selecciones de Franciscanismo 1987; 16: 403-436.

3. Martin S. El suicidio de San Francisco. Barcelona: Editorial Planeta; 1998.

4. Ros A. El ciego de Asís. México: Ediciones Oasis SA; 1959.

5. De Légisima JR, Gómez L. San Francisco de Asís. Madrid: La Editorial Católica SA; 1971. 